\title{
ORNL Slicer 2 v0.96 BETA
}

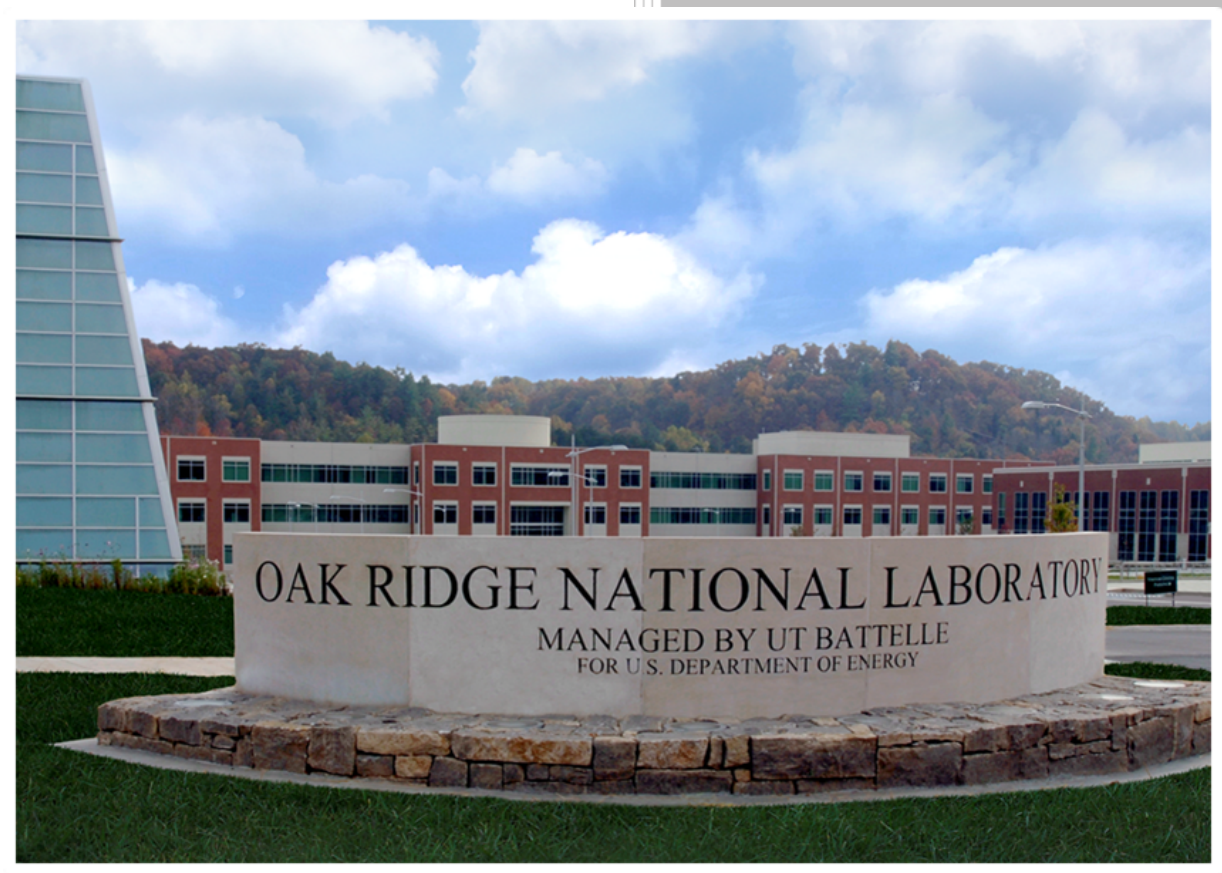

Alex Roschli

Michael Borish

Liam White

$10 / 1 / 2021$ 


\title{
DOCUMENT AVAILABILITY
}

Reports produced after January 1, 1996, are generally available free via US Department of Energy (DOE) SciTech Connect.

Website www.osti.gov

Reports produced before January 1, 1996, may be purchased by members of the public from the following source:

\author{
National Technical Information Service \\ 5285 Port Royal Road \\ Springfield, VA 22161 \\ Telephone 703-605-6000 (1-800-553-6847) \\ TDD 703-487-4639 \\ Fax 703-605-6900 \\ E-mail info@ntis.gov \\ Website http://classic.ntis.gov/
}

Reports are available to DOE employees, DOE contractors, Energy Technology Data Exchange representatives, and International Nuclear Information System representatives from the following source:

Office of Scientific and Technical Information

PO Box 62

Oak Ridge, TN 37831

Telephone 865-576-8401

Fax 865-576-5728

E-mail reports@osti.gov

Website http://www.osti.gov/contact.html

This report was prepared as an account of work sponsored by an agency of the United States Government. Neither the United States Government nor any agency thereof, nor any of their employees, makes any warranty, express or implied, or assumes any legal liability or responsibility for the accuracy, completeness, or usefulness of any information, apparatus, product, or process disclosed, or represents that its use would not infringe privately owned rights. Reference herein to any specific commercial product, process, or service by trade name, trademark, manufacturer, or otherwise, does not necessarily constitute or imply its endorsement, recommendation, or favoring by the United States Government or any agency thereof. The views and opinions of authors expressed herein do not necessarily state or reflect those of the United States Government or any agency thereof. 
Manufacturing Science Division

\title{
ORNL Slicer 2 v0.96 BETA Technical Memo
}

\author{
Alex Roschli \\ Michael Borish \\ Liam White
}

Date Published:

$10 / 1 / 2021$

Prepared by OAK RIDGE NATIONAL LABORATORY

Oak Ridge, TN 37831-6283

managed by

UT-BATTELLE, LLC

for the

US DEPARTMENT OF ENERGY

under contract DE-AC05-00OR22725 



\section{CONTENTS}

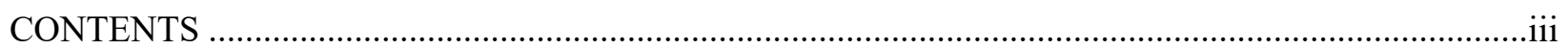

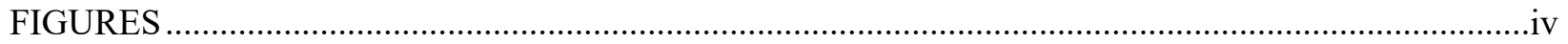

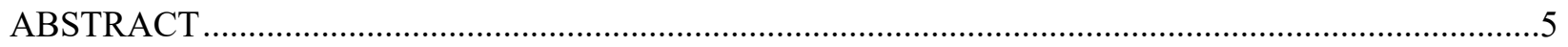

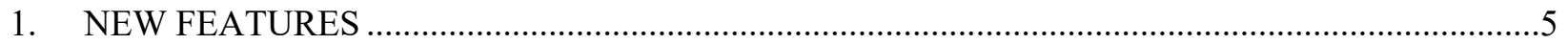

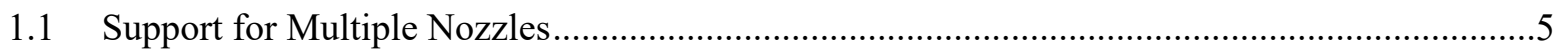

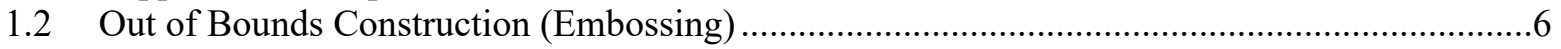

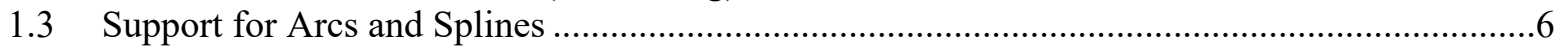

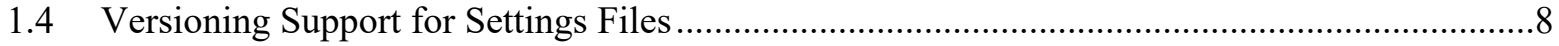

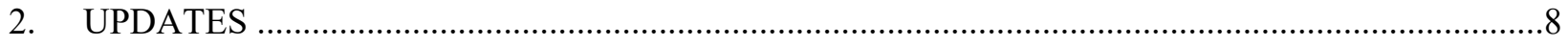

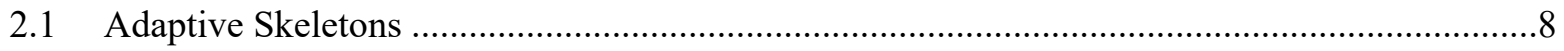

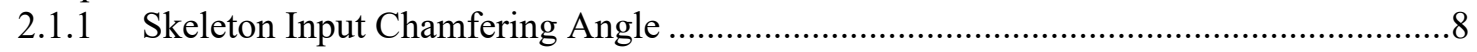

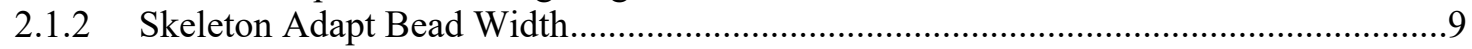

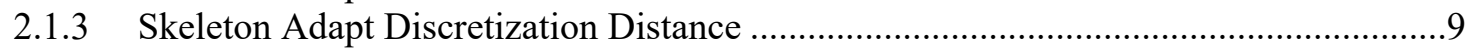

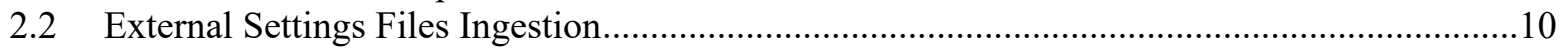

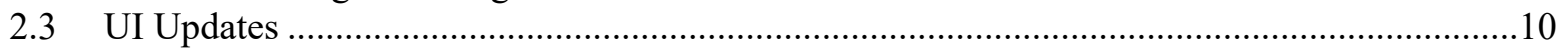

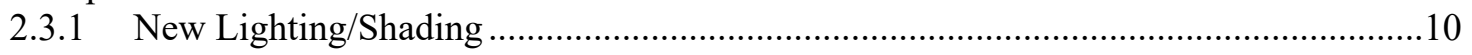

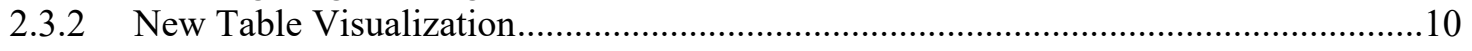

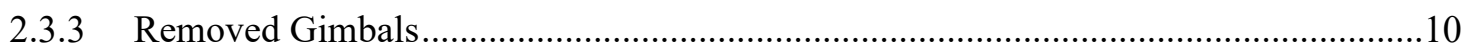

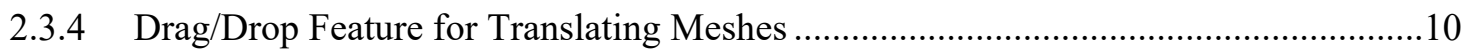

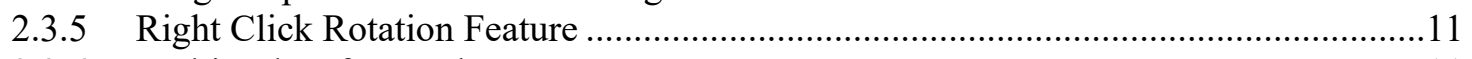

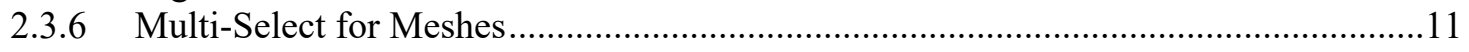

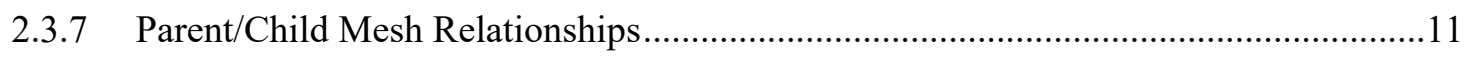

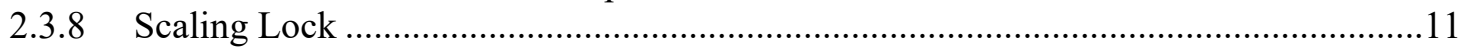

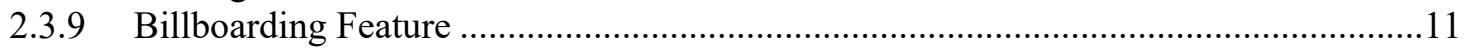

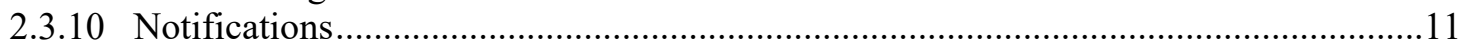

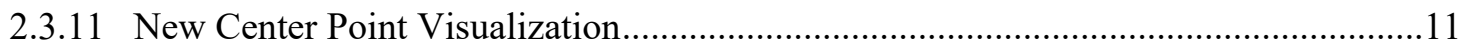

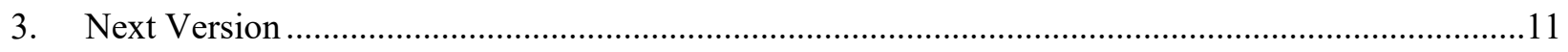




\section{FIGURES}

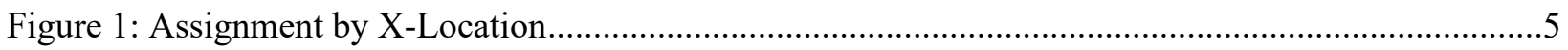

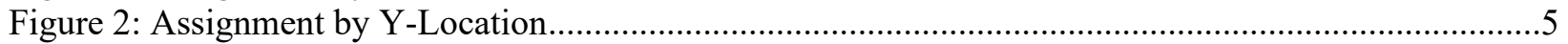

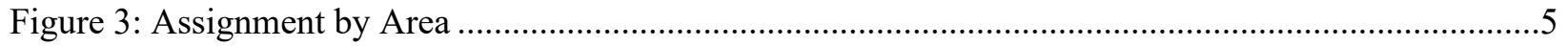

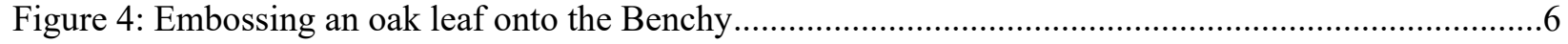

Figure 5: An oak leaf embossed onto the surface of a metal wall ..........................................................6

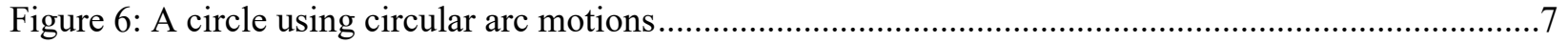

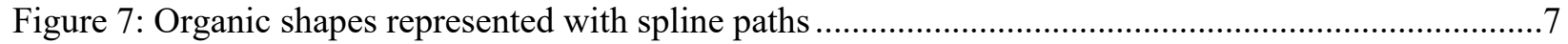

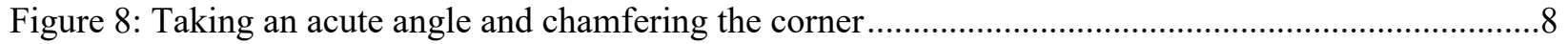

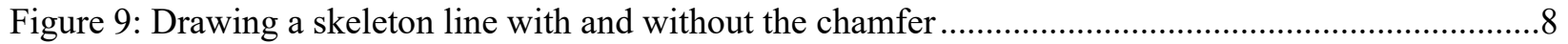

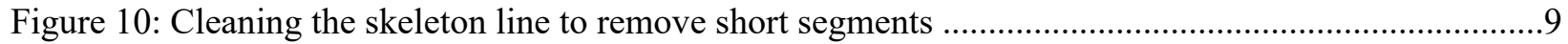

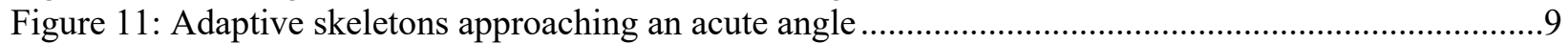

Figure 12: Decreasing the discretization distance to create more segments ..........................................10 


\begin{abstract}
ORNL Slicer 2 v0.96 BETA is the seventh BETA release of the ORNL Slicer 2 software package. It was released on 9/1/2021 to all users of v0.95, currently totaling over 100 users. This technical memo will highlight all of the new features, updates, and bug fixes released in this latest iteration of the ORNL Slicer 2 .
\end{abstract}

\title{
1. NEW FEATURES
}

\subsection{SUPPORT FOR MULTIPLE NOZZLES}

Multi-head construction is a relatively new hardware concept used for increasing build rates. This involves two or more independent extruder heads working collaboratively to build one object, or multiple objects, in the most efficient way possible. Initial implementation of these concepts at ORNL has started in preparation for these next generation systems. Three methods of optimization are available for assigning parts/islands based on: X-location which is useful where the heads are separated in the X-axis, Y-location which is useful where the heads are separated in the Y-axis, and object area which is useful for trying to equalize build times and material use.

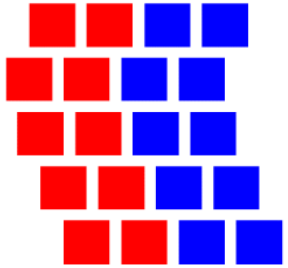

2 Extruders

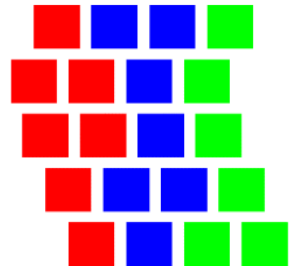

3 Extruders

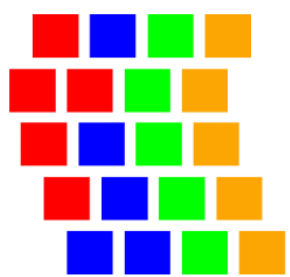

4 Extruders

Figure 1: Assignment by X-Location

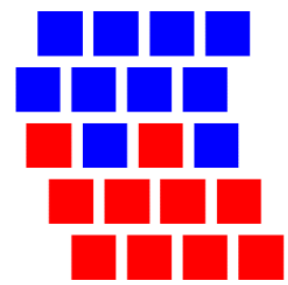

2 Extruders

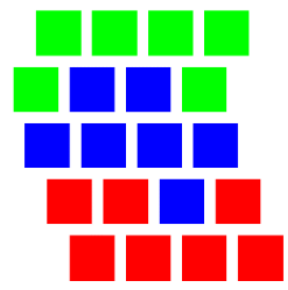

3 Extruders

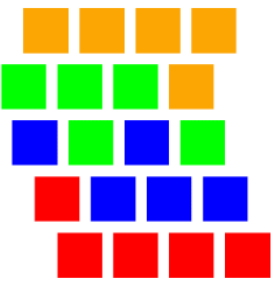

4 Extruders

Figure 2: Assignment by Y-Location

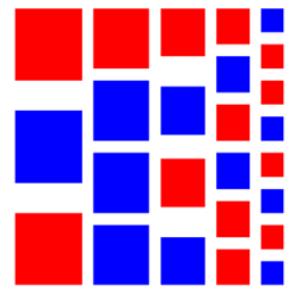

2 Extruders

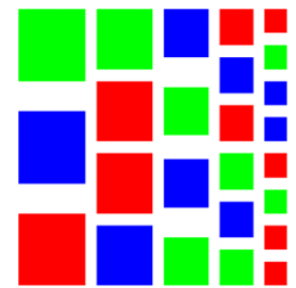

3 Extruders

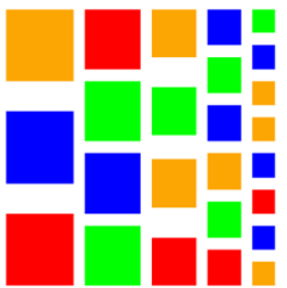

4 Extruders

Figure 3: Assignment by Area 


\subsection{OUT OF BOUNDS CONSTRUCTION (EMBOSSING)}

Embossing, a means of out of bounds construction, is useful for representing an object on the surface of another object. For example, the ORNL Oak Leaf can be embossed onto the surface of another object as a means of branding. The implementation for this construction methodology can be applied to any machine type, though each machine may execute the construction differently. The fundamental algorithm works by overlaying and intersecting one STL with another so that the geometry of one object can be wrapped onto the surface of the other for embossing. Figure 4 shows the graphical representation for the overlaying process.

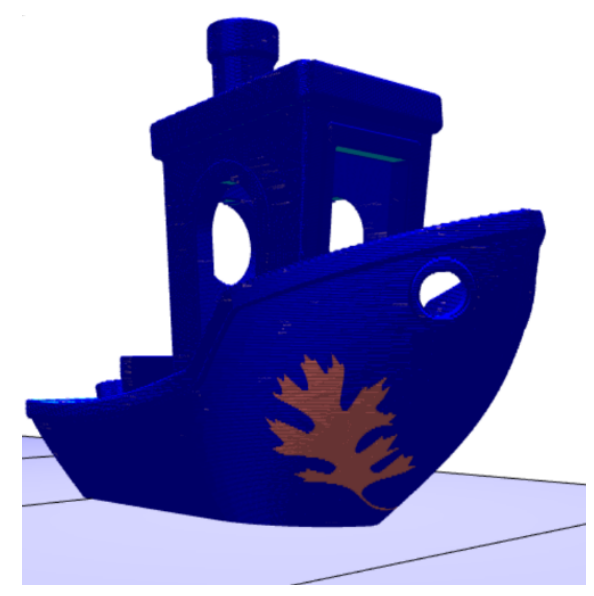

Figure 4: Embossing an oak leaf onto the Benchy

Once the object has been overlaid and wrapped onto the surface, as shown in Figure 4, the toolpaths must be modified to create the ideal end result. Some systems can build the embossed object in 3D wherein the new shape will create $\mathrm{X}$ and $\mathrm{Y}$ moves to form toolpaths of the new object. While other systems can simply modulate extruder or laser power to show the embossed object on the surface. Figure 5 shows a metal part where the laser power was modulated to create the oak leaf shape.
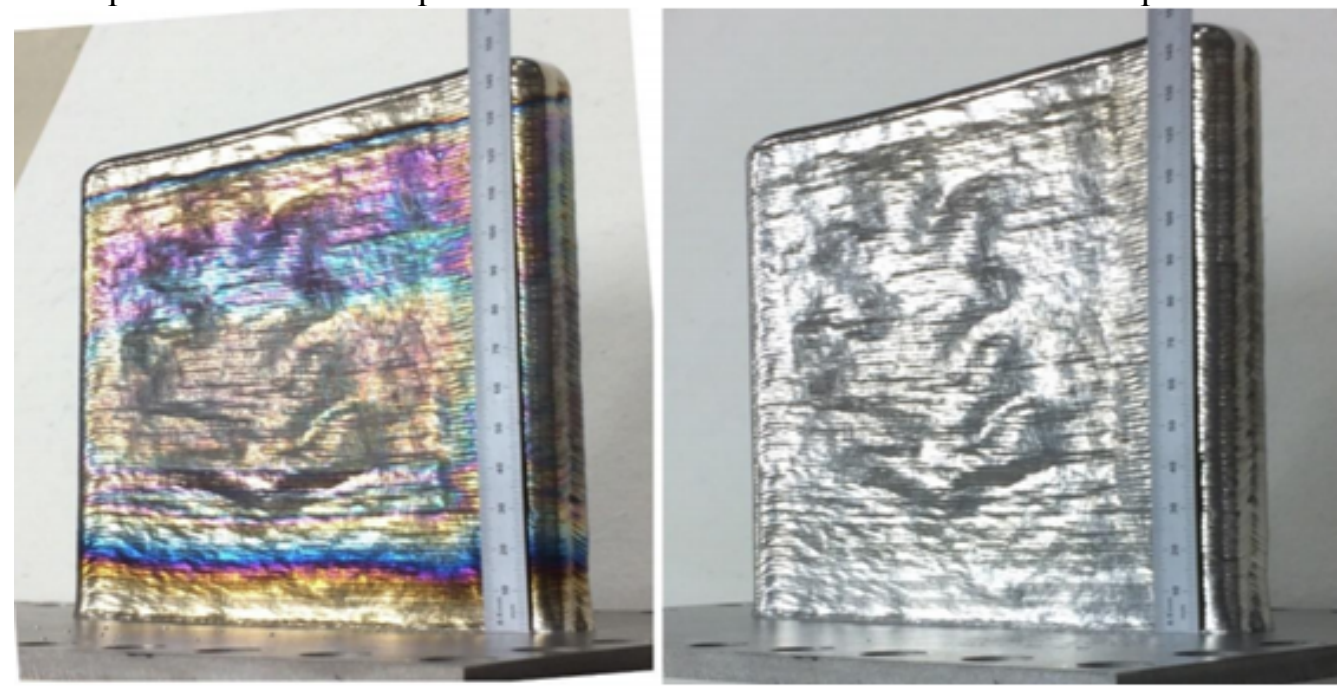

Figure 5: An oak leaf embossed onto the surface of a metal wall 


\subsection{SUPPORT FOR ARCS AND SPLINES}

Arcs and splines, represented as G2, G3, and G5 moves in G-Code, are useful for creating more accurate shapes and toolpaths. Typical slicing approaches only output G1 motions to create extrusion toolpaths. These G1 motions are straight line, point to point motions. When attempting to draw more organic shapes, or even basic rounded shapes such as a circle, a series of straight lines causes a loss of accuracy. These straight lines come from the STL file, used for creating the toolpaths, which only has flat surfaces represented by triangles. STL files don't include any of the curvature data native to the CAD file used to create the STL.

A recent innovation with ORNL Slicer allows the creation of arc and spline motions from the straight-line polygons of the STL. Arc fitting is based on circular arcs and it works by finding line segments that can be represented by one arc motion, clockwise or counterclockwise. The resultant output command notes the start point, end point, radius of curvature, center point, and clockwise/counterclockwise direction. Figure 6 shows a circle represented with circular arc motions.

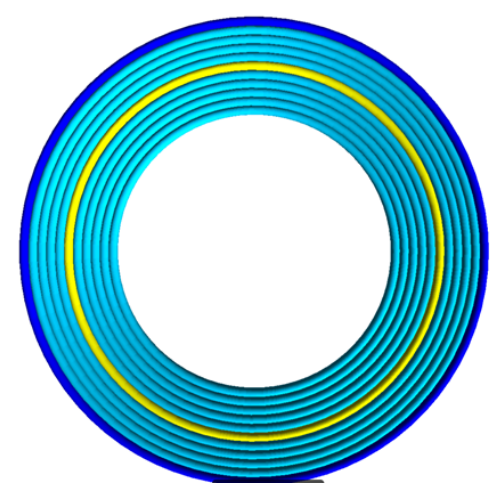

Figure 6: A circle using circular arc motions

Like arcs, splines can be used to represent the desired geometry of an object more accurately. Splines do not have to be circle-based, allowing them to be more useful for organic shapes. Splines can use cubic or quadratic equations to draw a path. Figure 7 shows an object with non-circular geometry represented with splines.

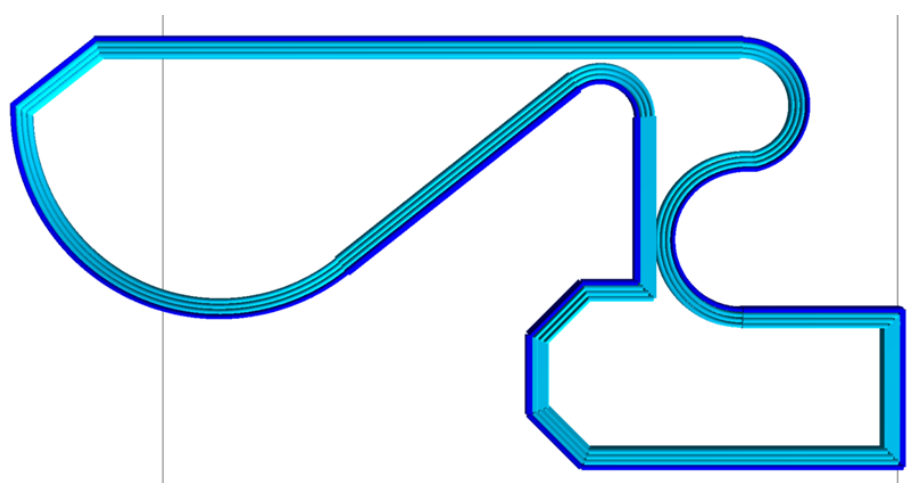

Figure 7: Organic shapes represented with spline paths

With both arcs and splines, the resultant G-Code file is smaller due to the decreased number of lines. The resultant printed object is often smoother because of the smoother motion from arcs and splines eliminating the tessellation often seen from straight line toolpaths. The arc and spline motions are 
interpolated by the $3 \mathrm{D}$ printer to create a smooth motion through the path with less accelerating and decelerating compared to a series of straight-line motions.

\subsection{VERSIONING SUPPORT FOR SETTINGS FILES}

Version 0.96 brings versioning of settings files as well as a header with more file specific information. Settings files are now versioned so that the Slicer ensures a loaded file is up to date and contains all the needed settings. If it is not up to date, the user will be prompted to have the file automatically updated. Also in the header is the name of the file creator, the date created, the date last modified, and a lock. The lock will be used to distinguish between locked templates that cannot be edited so the user always has a working file to use as an example.

\section{UPDATES}

\subsection{ADAPTIVE SKELETONS}

Skeletons are open-loop paths meant to fill voids that closed-loop paths cannot due to the size of their bead width. Prior to the update, Skeletons were not able to fill voids defined by sharp angles due to the nature of Voronoi diagram generation. This has been addressed through the inclusion of the user setting: Skeleton Input Chamfering Angle.

\subsubsection{Skeleton Input Chamfering Angle}

Acute regions of Skeleton input geometry defined by an angle less than the specified angle will be chamfered (squared off). Without chamfering, no Skeletons can be generated for these types of regions.
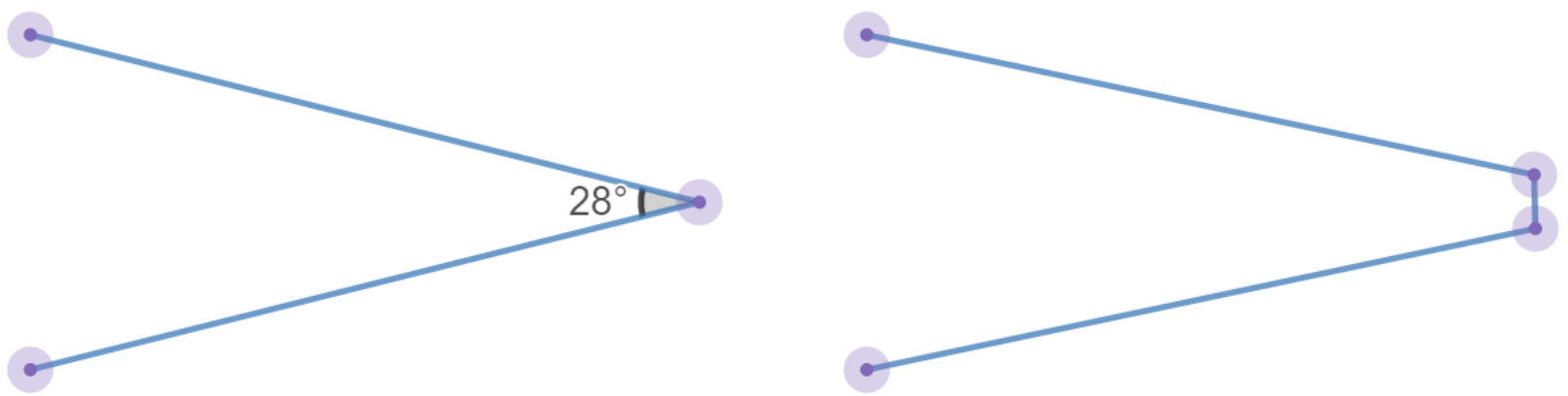

Figure 8: Taking an acute angle and chamfering the corner

The reasoning for this is because all acute corners will generate Skeletons originating from the corner; however, in most cases, Skeletons connecting to the boundary are unwanted and so are removed. By chamfering the acute corner by a minimum allowed distance, three Skeleton segments are generated with only two connecting to the boundary. 

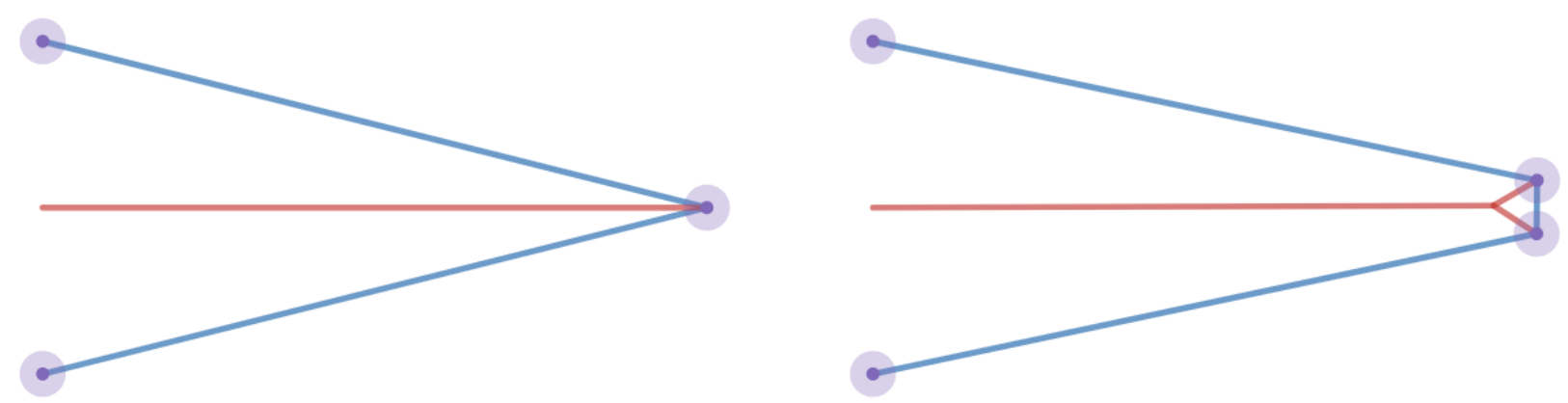

Figure 9: Drawing a skeleton line with and without the chamfer

The two segments connected to the boundary are removed via the normal cleaning process and the third segment running the length of the acute geometry is left for path generation.
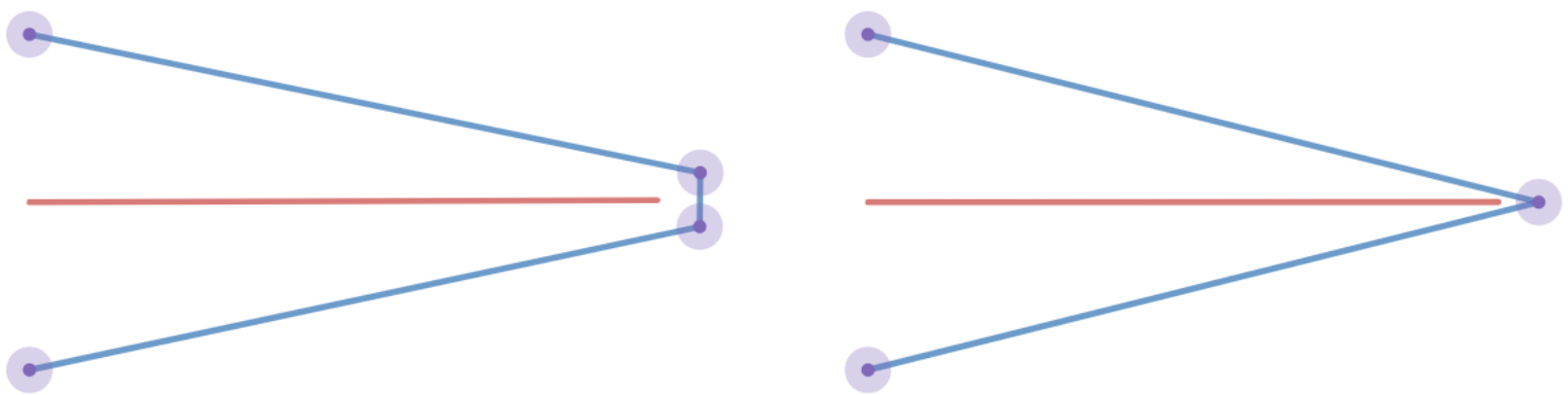

Figure 10: Cleaning the skeleton line to remove short segments

Before the update, all Skeleton segments were assigned the same bead width specified by the user. For tapered regions such as the one featured above, this resulted in either under- or over-filled regions depending on the set bead width. This has been addressed by the inclusion of two user settings; Skeleton Adapt Bead Width and Skeleton Adapt Discretization Distance.

\subsubsection{Skeleton Adaptive Bead Width}

When enabled, Skeleton segment bead widths will adapt so that segments better fill their environment. In doing so, over-filling is eliminated, and under-filling is minimized. Individual segment bead widths are adjusted according to the relationship set by the user between the nominal Skeleton bead width and Skeleton speed.
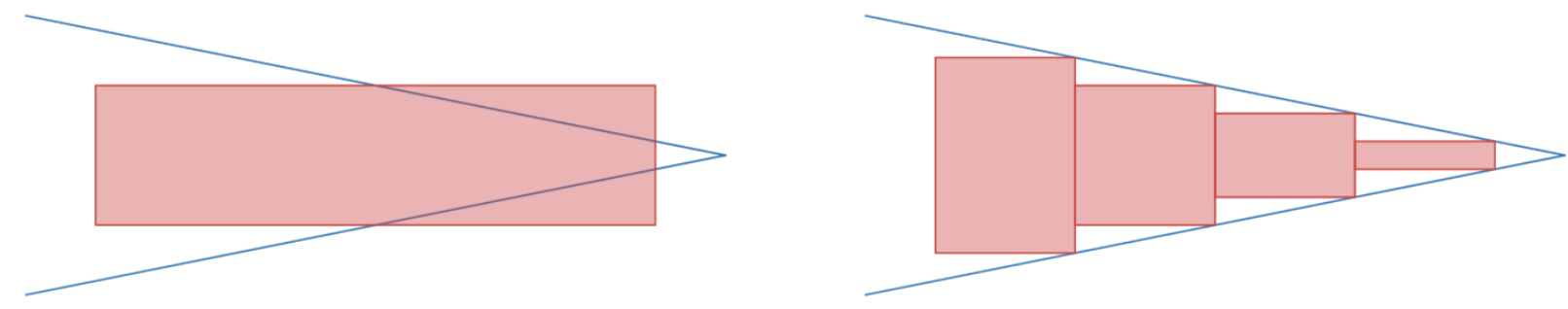

Figure 11: Adaptive skeletons approaching an acute angle

The way in which Skeleton segments adapt to their environment is through the subdivision of each segment according to the specified Skeleton Adapt Discretization Distance set by the user. 


\subsubsection{Skeleton Adaptive Discretization Distance}

Skeleton segments are divided into $N$ adaptable subsegments according to $N=\frac{S S L}{S D D}$, where $S L L$ is the original Skeleton segment length and $S D D$ is the Skeleton discretization distance. The discretization distance is inversely proportional to the rate of adaptation and so a smaller discretization distance will result in more adaptable subsegments being generated and thus a better adaptation. So as not to have too many adapted subsegments, subsegments with similar adapted bead widths are grouped together to form larger subsegments.
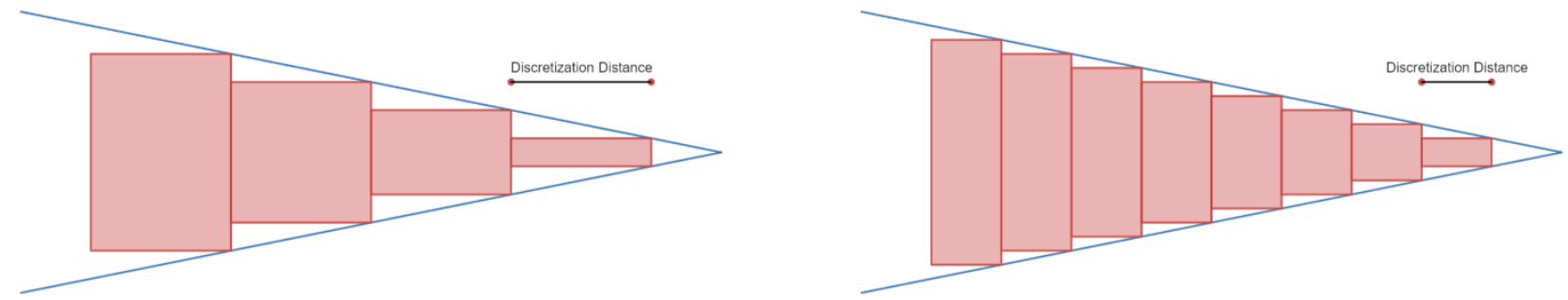

Figure 12: Decreasing the discretization distance to create more segments

\subsection{EXTERNAL SETTINGS FILES INGESTION}

Settings files are now ingested to the software externally with a new location. This change allows settings files to be stored in an easy to access templates folder and allows for manual file selection when creating an installer. This allows for selecting only certain files from the templates folder to be included when making an executable version of the slicer. Previously, the settings were held internally to the source code in a folder that could not be excluded, meaning all of the settings files were part of every installer. To cut down on clutter for users with only one system type, and to preserve any company sensitive information that may be contained in settings files, the templates folder is now used and only includes generic settings files and information.

\subsection{UI UPDATES}

Version 0.96 sees a significant number of updates to the UI and visualization. This includes new buttons, new features, improved rendering, and much more. Many of the specific updates are listed below with a short description.

\subsubsection{New Lighting/Shading}

New lighting and shading have been implemented for the part view and G-Code view. This makes it easier to see edges and understand the boundaries and geometry of objects.

\subsubsection{New Table Visualization}

The table, also known as the build plate, is now highlighted in blue as part of the part view tab. This helps to better understand what is being visualized and use it as a reference for alignment.

\subsubsection{Removed Gimbals}

The gimbals, available through a button in the sidebar of the part view, were used to drag an object for rotating and translating. They were helpful, but clunky. They also required on additional click to enable and disable as compared to the new functionality to be outlined in the following sections. 


\subsubsection{Drag/Drop Feature for Translating Meshes}

A selected object can now be translated with a left click and drag approach. This replaces the gimbal functionality for translation. While translating an object in this manner, a grid will appear over the build plate for help with alignment.

\subsubsection{Right Click Rotation Feature}

A selected object can now be rotated with a right click and drag approach. Rotation snaps to 15-degree intervals to help with easier alignment. This replaces the gimbal functionality for rotation.

\subsubsection{Multi-Select for Meshes}

Multiple meshes can now be selected from the object list in the part view tab. To do this, select an object, hold CTRL, and select one or more additional objects. Once multiple objects are selected, the group can be collectively translated or rotated using the functionality outlined in 2.3.4 and 2.3.5.

\subsubsection{Parent/Child Mesh Relationships}

A mesh can now be the parent of other meshes by selecting and object and moving it on top of the desired parent in the object list. Once a parent-child relationship has been established, rotations, translations, and scaling can be applied equally to all objects in the relationship.

\subsubsection{Scaling Lock}

Scaling an object can be done independently about the X, Y, and Z axes. However, to uniformly scale an object, the scale value must be typed into each of the three scaling boxes. With a new update, a lock button is available which keeps the scale value the same among all boxes. So, if one box is updated, this value is transferred to the other two boxes.

\subsubsection{Billboarding Feature}

When several STL files are present in the workspace, it can be difficult to quickly see which is which among all the versions. A new feature, billboarding, displays the file name on top of the mesh visualization so that each mesh can quickly be identified.

\subsubsection{Notifications}

A notification system has been implemented at the bottom of the part view tab to notify the user when an error is detected. These errors show up in red and provide useful feedback, such as an object not being properly aligned, to the user without being intrusive.

\subsubsection{New Center Point Visualization}

When translating the view, a small copy of the unit axes will show in the middle of the screen to allow a user to identify where the center is and its relative orientation to the build volume.

\section{NEXT VERSION}

The next version, ORNL Slicer 2 v0.97 BETA, is schedule for release on or about 9/28/21. 